\title{
Ab-initio molecular dynamics model for density, elastic properties and short range order of Co-Fe-Ta-B metallic glass thin films
}

\author{
C. Hostert ${ }^{a, *}$, D. Music ${ }^{a}$, J. Bednarcik ${ }^{b}$, J. Keckes ${ }^{c}$, V. Kapaklis ${ }^{d}$, B. \\ Hjörvarsson ${ }^{d}$, J.M. Schneider ${ }^{a}$
}

a Materials Chemistry, RWTH Aachen University, D-52056 Aachen, Germany

${ }^{b}$ Deutsches Elektronen Synchrotron DESY, D-22607 Hamburg, Germany

${ }^{c}$ Department of Materials Physics, Montanuniversität Leoben and Erich Schmid Institute for Materials Science Austrian Academy of Sciences, A-8700 Leoben, Austria

${ }^{d}$ Department of Physics and Materials Science, Uppsala University, Box 530, 75121 Uppsala, Sweden

Density, elastic modulus and the pair distribution function of Co-Fe-Ta-B metallic glasses were obtained by ab-initio molecular dynamics simulations and measured for sputtered thin films using X-ray reflectivity, nanoindentation and X-ray diffraction using high energy photons. The computationally obtained density of $8.19 \mathrm{~g} / \mathrm{cm}^{3}$ for $\mathrm{Co}_{43} \mathrm{Fe}_{20} \mathrm{Ta}_{5.5} \mathrm{~B}_{31.5}$ and $8.42 \mathrm{~g} / \mathrm{cm}^{3}$ for $\mathrm{Co}_{45.5} \mathrm{Fe}_{24} \mathrm{Ta}_{6} \mathrm{~B}_{24.5}$, as well as the Young's moduli of 273 and $251 \mathrm{GPa}$, respectively, are consistent with our experiments and literature data. These data, together with the good agreement between the theoretical and the experimental pair distribution functions, indicate that the here established model is useful to describe density, elasticity and short range order of Co-Fe-Ta-B metallic glass thin films. Irrespective of the investigated variation in chemical composition, (Co,Fe)-B cluster formation and Co-Fe interactions are identified by density of states analysis. Strong bonds within the structural units and between the metallic species may give rise to the comparatively large stiffness.

Keywords: metallic glasses, Co-Fe-Ta-B, ab-initio calculations, thin film

* Corresponding author. Tel.: +49 24180 25976; fax: +49 2418022295.

E-mail address: hostert@mch.rwth-aachen.de (C. Hostert). 


\section{Introduction}

$\mathrm{Co}_{43} \mathrm{Fe}_{20} \mathrm{Ta}_{5.5} \mathrm{~B}_{31.5}$ shows an extraordinary high fracture strength of $5185 \mathrm{MPa}[1,2,3]$, a Young's modulus of $268 \mathrm{GPa}[1,2,3]$, as well as a tensile strain of $1400 \%$ in the supercooled liquid region [2]. Furthermore, soft magnetic properties have been measured; an extremely high permeability of 550,000 [1] and a tailorable spin reorientation transition with the Curie temperature up to $450 \mathrm{~K}[4,5,6]$ were reported. Experiments on the corrosion properties show passivity in $\mathrm{NaCl}, \mathrm{HCl}$ and $\mathrm{H}_{2} \mathrm{SO}_{4}$ with corrosion rates in the order of $10^{-3} \mathrm{~mm} /$ year [7]. This property combination enables the application thereof as structural as well as magnetic material. Potential applications for $\mathrm{Co}_{43} \mathrm{Fe}_{20} \mathrm{Ta}_{5.5} \mathrm{~B}_{31.5}$ as magnetic material are magnetic head cores, thin film inductors, transformer cores as well as quick-response magnetic sensors $[4,8]$.

Kaban et al. [9] studied the atomic structure of $\mathrm{CO}_{43} \mathrm{Fe}_{20} \mathrm{Ta}_{5.5} \mathrm{~B}_{31.5}$ metallic glass and its effect onto glass-forming ability and thermal stability by X-ray diffraction and absorption experiments as well as by reverse Monte Carlo modeling. They proposed that the presence of Ta-B and B-B bonds, which are not existent in the crystalline state, account for the high glass-forming ability and thermal stability. Furthermore they reported Co-B to exhibit the shortest interatomic distance followed by B-B and Fe-B, indicating a strong bonding between the corresponding atoms.

Computational methods such as (ab-initio) molecular dynamics $[10,11,12,13,14]$, as well as extended X-ray absorption fine structure [10] and anomalous X-ray scattering measurements [15] were utilized to describe the spatial types of (chemical) short range order for several model binary metallic glasses [10], $\mathrm{Ni}_{25} \mathrm{Zr}_{60} \mathrm{Al}_{15}$ [11], $\mathrm{Fe}-\mathrm{Nb}-\mathrm{B}$ [12], $\mathrm{Fe}_{78} \mathrm{Si}_{9} \mathrm{~B}_{13}$ [13], $\mathrm{Cu}_{46} \mathrm{Zr}_{46} \mathrm{Al}_{8}$ [14] and $\mathrm{Cu}-\mathrm{Zr}-\mathrm{Al}$ [15]. Either trigonal prisms [11,12] or icosahedra/Kasper polyhedra with different center atoms $[10,11,13,14,15]$ were 
reported to be the structural basis of these metallic glasses. A few ab-initio reports on elasticity of amorphous steels are available [16,17], aiming to identify alloying elements which give rise to ductility. An elasticity-electronic structure correlation for $\mathrm{Co}_{43} \mathrm{Fe}_{20} \mathrm{Ta}_{5.5} \mathrm{~B}_{31.5}$ or other metallic glasses does not seem to be reported yet.

In this work, we establish and validate a model to study the correlation between the elastic properties of Co-Fe-Ta-B metallic glasses and the electronic structure thereof. The validation was achieved by experimental replication of the pair distribution function (PDF), density and elasticity. Furthermore, the calculated data are consistent with literature data for bulk metallic glasses of identical composition. The comparatively large stiffness of 190-209 GPa may be understood based on the electronic structure. The formation of $\mathrm{Co}-\mathrm{B}$ and $\mathrm{Fe}-\mathrm{B}$ clusters as well as a strong metallic Co-Fe interaction give rise to this large stiffness. Furthermore composition variations in the range from $\mathrm{Co}_{43} \mathrm{Fe}_{20} \mathrm{Ta}_{5.5} \mathrm{~B}_{31.5}$ to $\mathrm{Co}_{45.5} \mathrm{Fe}_{24} \mathrm{Ta}_{6} \mathrm{~B}_{24.5}$ do not seem to affect the bonding nature and hence the elastic properties and density.

\section{Theoretical methods}

$A b$-initio molecular dynamics, as implemented in the OpenMX code $[18,19]$, based on density functional theory [20] with generalized gradient approximation and linear combination of pseudoatomic orbitals [21], was used to correlate the elastic properties with the electronic structure of Co-Fe-Ta-B. The following basis functions were applied: B4.5-s2p2, Co5.5-s2p1d1, Fe5.0-s1p2d1 and Ta7.0-s2p1d1f1. In order to identify a suitable glass model describing this alloy, three different initial configurations of $\mathrm{Co}_{43} \mathrm{Fe}_{20} \mathrm{Ta}_{5.5} \mathrm{~B}_{31.5}$, based on stoichiometric bcc supercells with $\mathrm{Co}$, $\mathrm{Fe}$, Ta and $\mathrm{B}$ on ad hoc random positions, were evaluated. Boron was placed either on (i) substitutional sites (128 atoms), (ii) substitutional sites with $5 \%$ larger lattice 
parameter (128 atoms) or (iii) substitutional sites, including $10 \%$ randomly introduced vacancies independent of atomic species (115 atoms). All initial configurations were held at a temperature of $4000 \mathrm{~K}$ by scaling the velocities for $400 \mathrm{fs}$ and were then quenched to $0 \mathrm{~K}$. Initially the density of all configurations was set to be identical. At $0 \mathrm{~K}$ all configurations were relaxed in terms of atomic positions and volumes and treated as ferromagnetic. More method related details can be found elsewhere [22]. For configuration (iii), containing 115 atoms, the applied cooling rates to $0 \mathrm{~K}$ were infinite, $1 \times 10^{16}$ and $1 \times 10^{14} \mathrm{~K} / \mathrm{s}$. As the cooling rate during sputtering are estimated to be beyond $10^{10} \mathrm{~K} / \mathrm{s}$, reaching $10^{15} \mathrm{~K} / \mathrm{s}$ [23], the here studied cooling rates are relevant for the sputtering experiments conducted.

\section{Experimental methods}

To evaluate the ab-initio molecular dynamics model, Co-Fe-Ta-B thin films were deposited in a UHV-deposition system with a base pressure of $10^{-8}$ mbar. A combinatorial physical vapor deposition strategy was employed [24] based on cosputtering of $\mathrm{Co}, \mathrm{Fe}, \mathrm{Ta}$ (each with a purity of $99.95 \%)$ and B (99.5\% purity) targets. All targets measured 2" in diameter. For Co, Fe and Ta targets DC sputtering was utilized, for B a RF generator was employed. The power densities were 1.1, 0.6, 0.3 and $8.4 \mathrm{~W} / \mathrm{cm}^{2}$ for $\mathrm{Co}, \mathrm{Fe}, \mathrm{Ta}$ and B, respectively. For Ta a shutter, blocking $\sim 2 / 3$ of the target area, to decrease the Ta flux contributing to film growth, was installed. During sputtering the argon pressure of $4 \times 10^{-3}$ mbar was kept constant. Electrically grounded Si (100)-wafers were used as substrates, which were neither rotated nor intentionally heated. The target to substrate distance was $\sim 10 \mathrm{~cm}$ which results in a deposition rate of $\sim 7 \mathrm{~nm} / \mathrm{min}$. The thin film composition in the center of the sample was determined in a LEAP 3000X HR atom probe with a laser energy of 0.20-0.3 $\mathrm{nJ}$, 
a detection rate of $1.0-2.0 \%$, base temperature of $30-60 \mathrm{~K}$ and a pulse rate of $250 \mathrm{kHz}$ as well as in a LAWATAP system with a sample temperature of $40-50 \mathrm{~K}$, using laser pulsing mode, UV irradiation and detection rates of 0.01-0.05 ions/pulse. The structure of the deposited film was determined using a grazing incidence X-ray diffractometer (Bruker D8, Cu $\mathrm{K}_{\alpha}$ irradiation), X-ray reflectivity (XRR) measurements were carried out with a Philips PW1820 diffractometer using $\mathrm{Cu} \mathrm{K}_{\alpha}$ radiation and subsequent fitting of the experimental curves using the GenX software [25]. The thin film stiffness was measured using a depth-sensing nanoindenter (Hysitron TribolndenterTM) attached with a Berkovich indenter tip. For each measurement 18 indentations were carried out. The loads were varied between 800 and $2500 \mathrm{mN}$, which correspond to a contact depth of $<10 \%$ of the films thickness. Fused silica and sapphire were employed for tip calibration according to the method of Oliver and Pharr [26].

Pair distribution functions (PDFs) were extracted from X-ray diffraction (XRD) experiments using high-energy photons with the BW5 wiggler beamline of DORIS III positron storage ring, DESY/HASYLAB. Ten independent scans at room temperature were acquired in transmission mode with $100 \mathrm{keV}(\lambda=0.01239 \mathrm{~nm}), 10$ s illumination time, a fast image plate detector and a detector to sample distance of $51.3 \mathrm{~cm}$ for a high- $q$ range cover of up to $18.5 \AA^{-1}$. Two-dimensional XRD patterns were integrated to the $q$-space using the software package FIT2D [27]. The data were then converted to the total structure factor, $S(q)$, using standard procedures described elsewhere [28]. The integrated data were corrected for sample absorption, fluorescence contribution and inelastic (Compton) scattering. The total structural factor $S(q)$ is obtained from the normalized elastically scattered intensity, $l_{e}(q)$ 


$$
S(q)=1+\frac{I_{e}(q)-\left[\sum_{i=1}^{n} c_{i} f_{i}^{2}(q)\right]}{\left[\sum_{i=1}^{n} c_{i} f_{i}(q)\right]^{2}}
$$

where $c_{i}$ and $f_{i}(q)$ are the atomic concentrations and scattering factors of the atomic species of type $\mathrm{i}(\mathrm{i}=\mathrm{Co}, \mathrm{Fe}, \mathrm{Ta}, \mathrm{B})$, respectively. The corresponding reduced pair distribution function, $G(r)$, can be obtained through a sine Fourier transformation:

$$
G(r)=4 \pi r\left[\rho(r)-\rho_{0}\right]=\frac{2}{\pi} \int_{0}^{q_{\max }} q(S(q)-1) \sin (r q) d q
$$

where $\rho(r)$ and $\rho_{0}$ are the local and average atomic number densities, respectively, and $r$ is the radial distance. From $G(r)$ the PDF, $g(r)$ can be calculated by:

$$
g(r)=\frac{\rho(r)}{\rho_{0}}=\frac{G(r)}{4 \pi \rho_{0} r}+1
$$

A PDF, $g(r)$ can also be calculated from the structural model like the one presented in this study, using the relation

$$
g(r)=\frac{1}{4 \pi \rho_{0} r^{2}} \sum_{i} \sum_{j} \frac{b_{i} b_{j}}{\langle b\rangle^{2}} \delta\left(r-r_{i j}\right)(4),
$$

where the sum goes over all pairs of atoms $i$ and $j$ within the model separated by $r_{i j}$. The $b_{i}$ denotes the scattering power of atom $\mathrm{i}$ and $\langle\mathrm{b}\rangle$ is the average scattering power of the sample.

4. Results and discussion

The discussion of a suitable configuration to describe the quaternary metallic glass system under study here is based on the total energy of each supercell. The 
quantitative deviation in total energy for all configurations with reference to configuration (iii) can be found in table 1. It is shown here that the initial configuration (iii), containing vacancies, results in a 43 and $2 \mathrm{meV} /$ atom lower total energy than for configuration (i) and (ii), respectively. This corresponds to a relative deviation of $+0.6 \%$ and $+0.03 \%$, respectively. It appears that the bcc supercell vacancies provide pathways for diffusion. The total energy differences between configuration (iii) with infinite cooling and the two aforementioned cooling rates differ by -34 and -93 $\mathrm{meV} /$ atom or $-0.5 \%$ and $-1.2 \%$, respectively. Thus, the total energy of configuration (iii) does not significantly depend on the cooling rate. Based on the total energy analysis and CPU requirements, we hence selected configuration (iii) with an infinite cooling rate as the suitable description of the $\mathrm{C}_{43} \mathrm{Fe}_{20} \mathrm{Ta}_{5.5} \mathrm{~B}_{31.5}$ metallic glass.

Figure 1 shows exemplarily the initial and final configuration (iii) for $\mathrm{Co}_{43} \mathrm{Fe}_{20} \mathrm{Ta}_{5.5} \mathrm{~B}_{31.5}$. No evidence for long range ordering and formation of segregations can be seen. Hence this final configuration appears to be amorphous. While the composition for the ab-initio study was $\mathrm{Co}_{43} \mathrm{Fe}_{20} \mathrm{Ta}_{5.5} \mathrm{~B}_{31.5}$, the thin film composition in the center of the sample was determined based on the atom probe data to be $\mathrm{Co}_{45.5} \mathrm{Fe}_{24} \mathrm{Ta}_{6} \mathrm{~B}_{24.5}$. Hence an additional simulation with this experimentally obtained composition was conducted, keeping all other parameters constant to quantify the effect of a reduction in B concentration by 7 at $\%$ on the stiffness and density.

The structure of the deposited film was determined to be X-ray amorphous with a broad hump around two theta of $44-45^{\circ}$ (data not shown here). Density values were derived from ab-initio molecular dynamics and X-ray reflectivity measurements. The theoretical densities obtained from energy-volume curves are $8.19 \mathrm{~g} / \mathrm{cm}^{3}$ for $\mathrm{Co}_{43} \mathrm{Fe}_{20} \mathrm{Ta}_{5.5} \mathrm{~B}_{31.5}$ and $8.42 \mathrm{~g} / \mathrm{cm}^{3}$ for $\mathrm{Co}_{45.5} \mathrm{Fe}_{24} \mathrm{Ta}_{6} \mathrm{~B}_{24.5}$. XRR shows that the density of the deposited film is $\sim 8.80 \mathrm{~g} / \mathrm{cm}^{3}$. The theoretically obtained densities listed in 
table 2 and shown in figure 2 for $\mathrm{Co}_{43} \mathrm{Fe}_{20} \mathrm{Ta}_{5.5} \mathrm{~B}_{31.5}$ and $\mathrm{Co}_{45.5} \mathrm{Fe}_{24} \mathrm{Ta}_{6} \mathrm{~B}_{24.5}$ are in good agreement to the reported value for $\mathrm{Co}_{43} \mathrm{Fe}_{20} \mathrm{Ta}_{5.5} \mathrm{~B}_{31.5}$ bulk metallic glasses with $8.65 \mathrm{~g} / \mathrm{cm}^{3}$ [2] showing a deviation of $5 \%$ and $3 \%$, respectively. The thin film value measured in this study differs to the previously reported bulk value [2] by only $2 \%$; the deviations to the theoretical results of $\mathrm{Co}_{45.5} \mathrm{Fe}_{24} \mathrm{Ta}_{6} \mathrm{~B}_{24.5}$ and $\mathrm{Co}_{43} \mathrm{Fe}_{20} \mathrm{Ta}_{5.5} \mathrm{~B}_{31.5}$ are $5 \%$ and $7 \%$, respectively, indicating a weak dependence on the chemical composition in the here studied range. Based on the good agreement between calculated, previously reported and our measured thin film density we learn that the here established computational methodology is useful to describe the density of Co-Fe-Ta-B metallic glasses.

For further evaluation of the here proposed ab-initio molecular dynamics model, we compared the computationally obtained total PDF with the PDF extracted from X-ray diffraction experiments using high-energy photons. This approach was successfully implemented to characterize the (chemical) short range order of binary metallic glass systems by Sheng et. al [10]. The comparison of the computationally obtained PDF (obtained by analysing the ab-initio model using eq. (4)) and the experimental one, is given in figure 3. Both curves exhibit similar characteristic features indicating a valid replication. This provides strong backing of the first principles approach and its feasible implementation for short range order analysis of the quaternary, magnetic amorphous alloy studied here. Nearest neighbor analysis of the ab-initio data reveals that the dominant atomic pairs which determine the first coordination shell are (Co, $\mathrm{Fe})-(\mathrm{Co}, \mathrm{Fe}),(\mathrm{Co}, \mathrm{Fe})-\mathrm{Ta}$ and Ta-Ta. The small pre-peak located at $2.10 \AA$ can be assigned to the presence of $(\mathrm{Co}, \mathrm{Fe})-\mathrm{B}$ atomic pairs (see table 3). These results are consistent with experimental PDF analysis employing a hard sphere approach (sum of Goldschmidt radii in combination with X-ray weighting factors) as well as with the results obtained by Kaban et al. [9] utilizing the reverse Monte Carlo method. 
Relatively large standard deviations on (Co,Fe)-Ta interactions in this study may be due to the limited number of Ta in the supercell, causing poor statistics.

The inset of figure 3 shows the structure factor $S(q)$ of the amorphous thin film metallic glass. The sample exhibits a pronounced diffuse scattering pattern typical for metallic glasses with a maximum at $q \sim 3.1 \AA^{-1}$ and pronounced oscillations visible up to $q \sim 18.5 \AA^{-1}$. Further Fourier transformation of the structure factor, according to equation (2), lead to the reduced pair distribution function $G(r)$, which, in this case, indicates a missing of long-range order, which again is specific for metallic glasses (data not shown here). As an additional argument for the validity of our ab-initio model, we extracted a mean atomic density of $\rho_{0}=0.0944$ atoms $/ \AA^{3}$ (obtained by fitting $G(r)$ on low $r$-range $\langle 0,1.8\rangle \AA$ to the equation $\left.-4 \pi r \rho_{0}\right)$ or a respective mass density of $8.62 \mathrm{~g} / \mathrm{cm}^{3}$ from these XRD experiments, which differs to the thin film density obtained by the $\mathrm{X}$-ray reflectivity technique $(\mathrm{Cu} \mathrm{K}$ ) by $2 \%$, to the theoretical results by $2-5 \%$ depending on the simulation configuration and by only $0.4 \%$ to the reported bulk metallic glass density [2].

While the bulk modulus is calculated to be $209 \mathrm{GPa}$ by ab-initio molecular dynamics for $\mathrm{Co}_{43} \mathrm{Fe}_{20} \mathrm{Ta}_{5.5} \mathrm{~B}_{31.5}$ and $190 \mathrm{GPa}$ for $\mathrm{Co}_{45.5} \mathrm{Fe}_{24} \mathrm{Ta}_{6} \mathrm{~B}_{24.5}$, a reduced Young's modulus of $207 \pm 10 \mathrm{GPa}$ was measured experimentally. The Poisson's ratio of $\mathrm{Co}_{43} \mathrm{Fe}_{20} \mathrm{Ta}_{5.5} \mathrm{~B}_{31.5}$ metallic glass has not been reported in literature. Based on the calculation of Grüneisen constant [29], the Poisson's ratio can be extracted from the energy-volume curves. With the calculated Poisson's ratios of 0.283 and 0.280 for both configurations, nominal and experimental, respectively, one is able to extract the Young's modulus from the reduced Young's modulus value obtained by nanoindentation experiments as well as from computationally obtained bulk modulus using the isotropic approximation. 
From the reduced Young's modulus, a Young's modulus of $233 \pm 14 \mathrm{GPa}$ is derived using the calculated Poisson's ratio of 0.28 . A deviation of $13 \%$ with respect to the reported modulus of $268 \mathrm{GPa}$ for $\mathrm{Co}_{43} \mathrm{Fe}_{20} \mathrm{Ta}_{5.5} \mathrm{~B}_{31.5}$ by Inoue et al. [2] is obtained. The derived Young's moduli of 273 and 251 GPa from the calculated bulk moduli for $\mathrm{Co}_{43} \mathrm{Fe}_{20} \mathrm{Ta}_{5.5} \mathrm{~B}_{31.5}$ and $\mathrm{Co}_{45.5} \mathrm{Fe}_{24} \mathrm{Ta}_{6} \mathrm{~B}_{24.5}$ deviate to the reported bulk value [2] by only $2 \%$ and $6 \%$, respectively. The deviation between the ab-initio study data for $\mathrm{Co}_{43} \mathrm{Fe}_{20} \mathrm{Ta}_{5.5} \mathrm{~B}_{31.5}, \mathrm{Co}_{45.5} \mathrm{Fe}_{24} \mathrm{Ta}_{6} \mathrm{~B}_{24.5}$ and the indentation data for $\mathrm{Co}_{45.5} \mathrm{Fe}_{24} \mathrm{Ta}_{6} \mathrm{~B}_{24.5}$ is about $15 \%$ and $7 \%$, respectively. Elasticity results are shown in figure 2 ; see table 2 for all results reported in this study. The magnitude of the largest deviations reported between calculations and experiments is well within the expected range for the exchange correlation functionals used [30]. The differences observed for density and elasticity within both configurations probed in our ab-initio study are small, but significant. Similarly to the density data and the short range order data we observe good agreement between the calculated and measured elastic properties and summarize that the here established computational model is useful to describe the elasticity of Co-Fe-Ta-B metallic glass.

In order to correlate the elasticity data presented above with the electronic structure, we study the density of states. Figure 4 shows the total density of states for $\mathrm{Co}_{45.5} \mathrm{Fe}_{24} \mathrm{Ta}_{6} \mathrm{~B}_{24}$ as well as total and partial total density of states for the simulated $\mathrm{Co}_{43} \mathrm{Fe}_{20} \mathrm{Ta}_{5.5} \mathrm{~B}_{31.5}$ metallic glass. Only orbitals with the largest density of states are plotted: $3 d$ for Fe and $\mathrm{Co}, 5 d$ for Ta as well as $2 s$ and $2 p$ orbitals for $B$. It can be seen that the total bonding character is metallic in both Co-Fe-Ta-B compositions since the Fermi level is occupied. This overall (inter-)metallic character gives rise to the large Poisson's ratio, as discussed above. No significant difference in bonding can be identified between the two compositions investigated based on the total density of states. Hence, the properties investigated may be insensitive to compositional 
variations, as discussed above. The bonds are mainly characterized by the strong interaction between cobalt and iron, as can be seen in the partial density of states of $\mathrm{Co}_{43} \mathrm{Fe}_{20} \mathrm{Ta}_{5.5} \mathrm{~B}_{31.5}$. Fe-B and Co-B are the strongest hybridized states present; these boron clusters are again metallically bonded. The electronic structure data obtained here are in agreement with the pair distribution analysis conducted in this study and with literature [9], where Co-B bonds are reported to yield the shortest interatomic distance followed by B-B and Fe-B and thus indicate strong bonding. Hence, this fact is expected to be responsible for the large stiffness of this glass.

\section{Conclusions}

In conclusion, we have carried out an ab-initio study on the quaternary $\mathrm{C}_{45.5} \mathrm{Fe}_{24} \mathrm{Ta}_{6} \mathrm{~B}_{24.5}$ metallic glass and we have produced $\mathrm{X}$-ray amorphous thin films with an identical composition using combinatorial physical vapor deposition. The proposed ab-initio molecular dynamics model was validated by experimental PDF as well as density and elasticity data. Comparison of the experimental PDF with the one obtained by analysing the ab-initio model shows good agreement and indicates a successful replication of short range order. The density of $8.42 \mathrm{~g} / \mathrm{cm}^{3}$ obtained via ab-initio molecular dynamics for $\mathrm{Co}_{45.5} \mathrm{Fe}_{24} \mathrm{Ta}_{6} \mathrm{~B}_{24.5}$, is within $2-4 \%$ of the experimentally measured values of 8.62 and $8.80 \mathrm{~g} / \mathrm{cm}^{3}$. Good agreement is also observed for the Young's modulus of $\sim 233 \mathrm{GPa}$ obtained via nanoindentation of thin films and the $251 \mathrm{GPa}$ calculated by ab-initio molecular dynamics. The deviation between the computationally obtained value for $\mathrm{Co}_{45.5} \mathrm{Fe}_{24} \mathrm{Ta}_{6} \mathrm{~B}_{24.5}$ and the experimentally determined stiffness is $7 \%$. Both, density and stiffness values are consistent with previously reported bulk data [2] and can be understood based on the electronic structure. $\mathrm{Co}_{45.5} \mathrm{Fe}_{24} \mathrm{Ta}_{6} \mathrm{~B}_{24.5}$ consists of hybridized boron forming $\mathrm{Co}-\mathrm{B}$ and 
Fe-B clusters which are metallically interconnected. This overall (inter-)metallic character gives rise to large Poisson's ratio and, due to strong bonding, large stiffness. Hence the properties measured can be understood based on the presence of itinerant (metallic) and localized (hybridized) bonding between the constituents. The here compiled computational model is useful to describe correlations between electronic structure, elasticity, density as well as (chemical) short range order and hence provides the basis for future knowledge based design of glassy materials.

Acknowledgements

The authors would like to acknowledge Deutsche Forschungsgemeinschaft (DFG) within the Collaborative Research Center (SFB) 761 "Steel - ab initio" as well as CAMECA and Imago for the compositional analysis of the thin film. Financial support from the Zhejiang University-Helmholtz Research Collaboration Program is also gratefully acknowledged.

[1] Inoue A, Shen BL, Koshiba H, Kato H, Yavari AR Nat. Mater. 2000;2:661

[2] Inoue A, Shen BL, Koshiba H, Kato H, Yavari AR Acta Mat. 2004:52:1631-1637

[3] Inoue A, Shen BL, Chang CT Intermet. 2006;14:936

[4] Sharma P, Kimura H, Inoue A J. Appl. Phys. 2006;100:083902

[5] Sharma P, Kimura H, Inoue A, Arenholz E, Guo JH Phys. Rev. B 2006;73:052401

[6] Sharma P, Kimura H, Inoue A J. Appl. Phys. 2007;101:09N502

[7] Shen B, Pang S, Zhang T, Kimura H, Inoue A J. Alloys Comp. 2008;460:L11-L13

[8] Chen HS Chinese Journal of Physics 1990;28:407

[9] Kaban I, Jóvári P, Stoica M, Eckert J, Hoyer W, Beuneu B Phys. Rev. B. 
[10] Sheng HW, Luo WK, Alamgir FM, Bai JM, Ma E Nature 2006;439:419

[11] Guerdane M, Teichler H Phys. Rev. B 2001;65:014203

[12] Imafuku M, Sato S, Matsubara E, Inoue A J. Non-Cryst. Sol. 2002;312-314:589593

[13] Qin J, Gu T, Yang L, Bian X Appl. Phys. Lett. 2007;90:201909

[14] Fang HZ, Hui X, Chen GL, Liu ZK Appl. Phys. Lett. (2009);94:091904

[15] Cheng YQ, Ma E, Sheng HW Phys. Rev. Lett. 2009;102:245501

[16] Kazimirov VY, Louca D, Widom M, Gu XJ, Poon SJ, Shiflet GJ Phys. Rev. B 2008;78:054112

[17] Kazimirov VY Phys. Rev. B 2009;80:214117

[18] Ozaki T, Kino H Phys. Rev. B 2005;72:045121

[19] OpenMX version 3.5 was used in this study and are available at www.openmxsquare.org

[20] Hohenberg P, Kohn W Phys. Rev. 1964;136:B864

[21] Ozaki T Phys. Rev. B 2003;67:155108

[22] Music D, Schneider JM J. Phys.: Condens. Matter 2008;20:195203

[23] Barbee TW, Jr., Holmes WH, Keith DL, Pyzyna MK Thin Solid Films 1977;45:591-599

[24] Gebhardt T, Music D, Ekholm M, Abrikosov IA, von Appen J, Dronskowski R, Wagner D, Mayer J, Schneider JM Acta Mat. 2011;59:1493-1501

[25] Björck M, Andresson G J. Appl. Cryst. 2007;40:1174-1178

[26] Oliver WC, Pharr GM J. Mater. Res. 1992;7:1564

[27] Hammersley AP, Svensson SO, Hanfland M, Fitch AN, Häusermann D High Press. Res. 1996;14:235

[28] Egami T, Billinge SJL Underneath the Bragg Peaks: Structural analysis of complex materials, Pergamon Press, Elsevier, Oxford, England; 2003 
[29] Dugdale JS, MacDonald DKC Phys. Rev. B 1953;89:832

[30] Eriksson O Encyclopedia of Materials: Science and technology, Elsevier; 2006

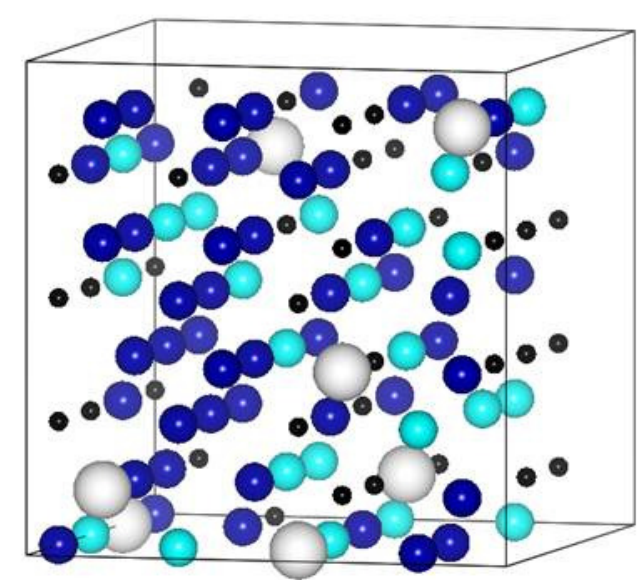

a)

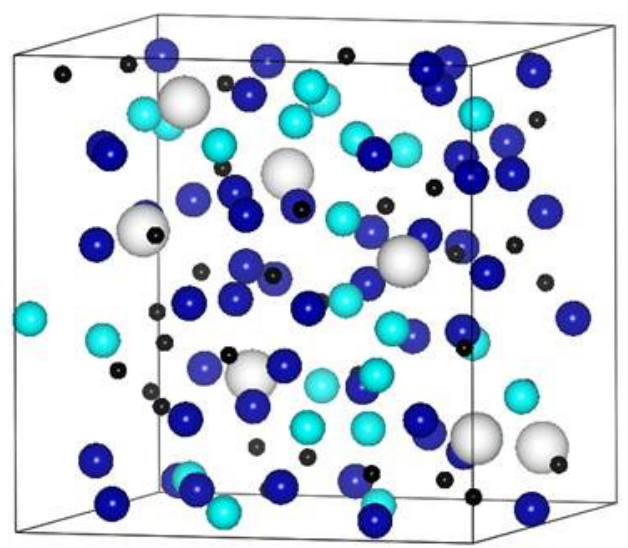

b)

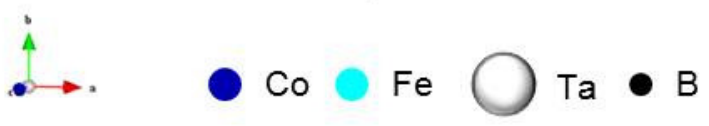

Figure 1: Configuration (iii) for $\mathrm{Co}_{43} \mathrm{Fe}_{20} \mathrm{Ta}_{5.5} \mathrm{~B}_{31.5}$ : (a) initial state and (b) after relaxation. 


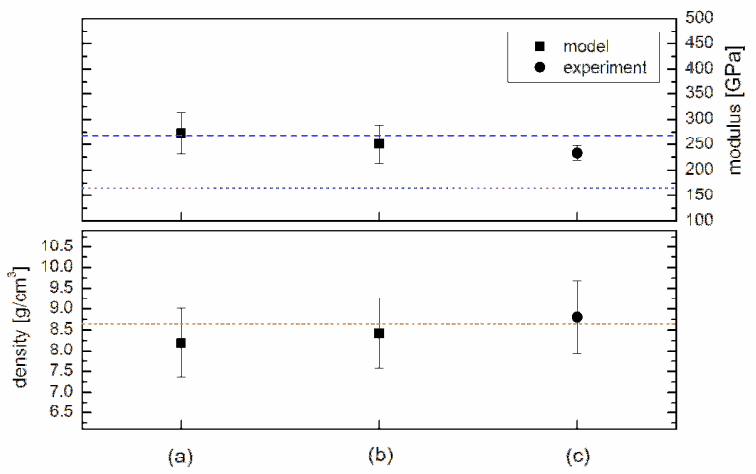

Figure 2: Obtained results for moduli and density within this work: a) ab-initio simulation, configuration iii, $\mathrm{Co}_{43} \mathrm{Fe}_{20} \mathrm{Ta}_{5.5} \mathrm{~B}_{31.5}$, b) ab-initio simulation, configuration iii, $\mathrm{Co}_{45.5} \mathrm{Fe}_{24} \mathrm{Ta}_{6} \mathrm{~B}_{24.5}, \mathrm{c}$ ) experimental results obtained by nanoindentation and XRR (Cu $\left.\mathrm{K}_{\alpha}\right)$, in comparison to [1] (dashed line) and [4] (dotted line).

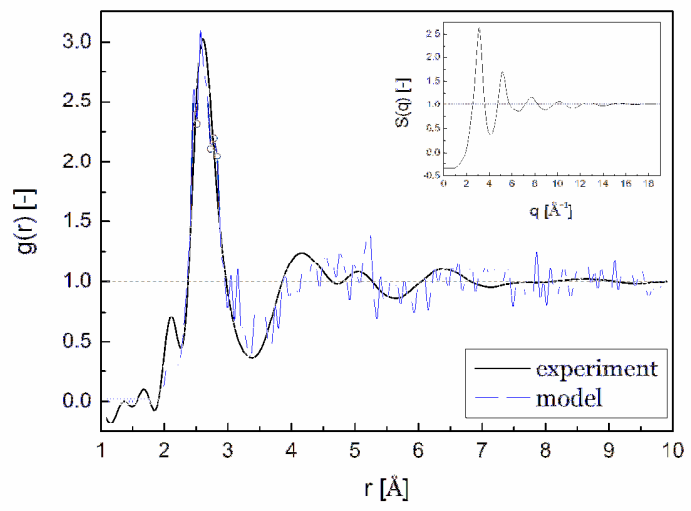

Figure 3: Computationally obtained total PDF (configuration iii, $\mathrm{Co}_{45.5} \mathrm{Fe}_{24} \mathrm{Ta}_{6} \mathrm{~B}_{24.5}$ ) and PDF extracted from $X$-ray diffraction experiments using high-energy photons. The structure factor $S(q)$ of the amorphous thin film metallic glass is shown in the inset. 


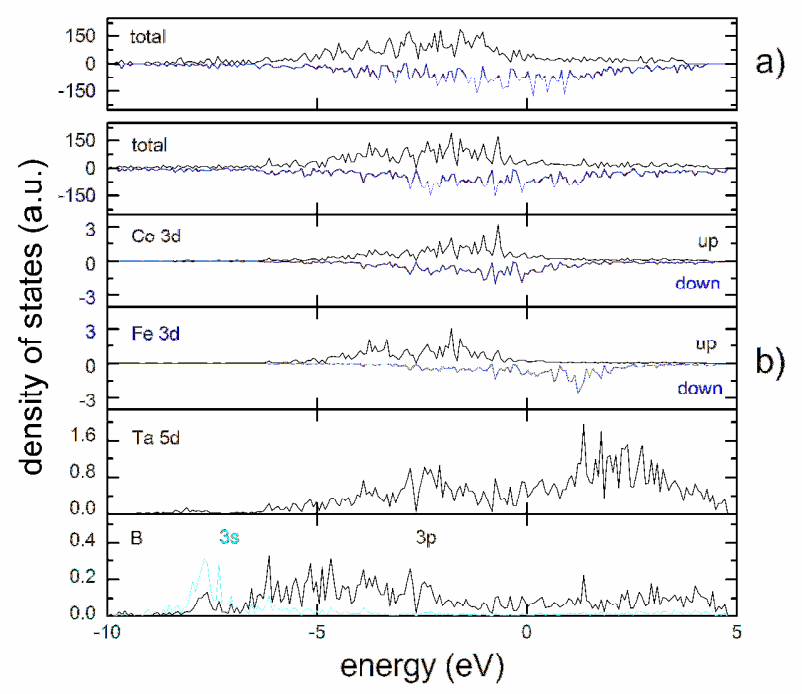

Figure 4: a) Total density of states for configuration (iii), $\mathrm{Co}_{45.5} \mathrm{Fe}_{24} \mathrm{Ta}_{6} \mathrm{~B}_{24.5}$, b) total and partial density of states for configuration (iii), $\mathrm{Co}_{43} \mathrm{Fe}_{20} \mathrm{Ta}_{5.5} \mathrm{~B}_{31.5}$. Fermi level is set to $0 \mathrm{eV}$. Up and down states are provided as positive and negative values, respectively. 
Table 1: Relative deviation in total energy $\left(\mathrm{U}_{\text {tot }}\right)$ of all probed configurations as obtained within the ab-initio study for $\mathrm{CO}_{43} \mathrm{Fe}_{20} \mathrm{Ta}_{5.5} \mathrm{~B}_{31.5}$ with reference to configuration (iii), infinitely cooling rate

\begin{tabular}{|c|c|c|c|c|c|c|}
\hline & \multirow[b]{2}{*}{ cooling rate } & \multicolumn{5}{|c|}{ configuration } \\
\hline & & $\begin{array}{c}\text { (i) } \\
\text { infinitely }\end{array}$ & $\begin{array}{c}\text { (ii) } \\
\text { infinitely }\end{array}$ & $\begin{array}{c}\text { (iii) } \\
\text { infinitely }\end{array}$ & $\begin{array}{c}\text { (iii) } \\
1 \times 10^{16} \mathrm{~K} / \mathrm{s} \\
\end{array}$ & $\begin{array}{c}\text { (iii) } \\
1 \times 10^{14} \mathrm{~K} / \mathrm{s}\end{array}$ \\
\hline$\Delta \mathrm{U}_{\text {tot }}[\mathrm{meV} /$ atom $]$ & & 43 & 2 & 0 & -34 & -93 \\
\hline
\end{tabular}

Table 2: Obtained results for bulk modulus, Poisson's ratio, reduced Young's modulus, Young's modulus and density

\begin{tabular}{cccccc}
\hline \hline & \multicolumn{2}{c}{ ab-initio } & \multicolumn{2}{c}{ experimental } \\
& \multicolumn{2}{c}{ this work, configuration (iii) } & this work & [1] & [4] \\
& $\mathrm{Co}_{43} \mathrm{Fe}_{20} \mathrm{Ta}_{5.5} \mathrm{~B}_{31.5}$ & $\mathrm{Co}_{45.5} \mathrm{Fe}_{24} \mathrm{Ta}_{6} \mathrm{~B}_{24.5}$ & & & \\
\cline { 2 - 6 } $\mathrm{B}[\mathrm{GPa}]$ & 209 & 190 & & & \\
$v$ & 0.283 & 0.280 & & & \\
$\mathrm{E}_{\mathrm{r}}[\mathrm{GPa}]$ & 273 & & 207 & \\
$\mathrm{E}[\mathrm{GPa}]$ & 8.19 & 251 & 233 & 268 & 166 \\
$\rho\left[\mathrm{g} / \mathrm{cm}^{3}\right]$ & 8.42 & $8.80^{\mathrm{a}} / 8.62^{\mathrm{b}}$ & 8.65 & \\
\hline \hline
\end{tabular}

a) this work by XRR, Cu $\left.K_{\alpha}, b\right)$ this work by XRD, high energy photons.

Table 3: Mean nearest neighbor distance for $\mathrm{Co}_{45.5} \mathrm{Fe}_{24} \mathrm{Ta}_{6} \mathrm{~B}_{24.5}$ metallic glass

\begin{tabular}{|c|c|c|c|c|c|}
\hline atomic pair & $\begin{array}{l}d_{i j}{ }^{a} \\
{[A]}\end{array}$ & $\begin{array}{c}\text { standard } \\
\text { deviation } \mathrm{d}_{\mathrm{ii}}\end{array}$ & $\begin{array}{l}\mathrm{R}_{\mathrm{ij}}{ }^{\mathrm{b}} \\
{[\AA \mathrm{A}]}\end{array}$ & $\begin{array}{c}\mathrm{W}_{\mathrm{ij}}^{\mathrm{b}} \\
{[-]}\end{array}$ & $\begin{array}{l}r_{i j}{ }^{c} \\
{[\AA]}\end{array}$ \\
\hline $\mathrm{Fe}-\mathrm{B} / \mathrm{B}-\mathrm{Fe}$ & 2.20 & 0.15 & 2.07 & 0.02022 & 2.20 \\
\hline Co-B/B-Co & 2.00 & 0.09 & 2.08 & 0.05404 & 2.02 \\
\hline Co-Co & 2.40 & 0.10 & 2.50 & 0.29418 & 2.52 \\
\hline Co-Fe/Fe-Co & 2.39 & 0.14 & 2.49 & 0.22021 & 2.51 \\
\hline $\mathrm{Fe}-\mathrm{Fe}$ & 2.45 & 0.10 & 2.48 & 0.04121 & 2.51 \\
\hline Co-Ta/Ta-Co & 2.68 & 0.24 & 2.68 & 0.22216 & 2.69 \\
\hline $\mathrm{Fe}-\mathrm{Ta} / \mathrm{Ta}-\mathrm{Fe}$ & 2.71 & 0.25 & 2.67 & 0.08315 & 2.73 \\
\hline
\end{tabular}

a) this work, ab-initio model, b) sum of Goldschmidt's radii $R_{i j}(1.25,1.24,1.43$ and $0.88 \AA$ for $\mathrm{Co}, \mathrm{Fe}, \mathrm{Ta}$ and $\mathrm{B}$ respectively) and corresponding $\mathrm{X}$-ray weighting factors $\boldsymbol{w}_{i j}$ calculated at $\left.q=0 \AA^{-1}, c\right)$ mean nearest neighbor distances from [9] 